\title{
THE USE OF NUMERICAL EXPERIMENTS ON A METAPOPULATION MODEL AND REMOTE SENSING DATA FOR REEF CONSERVATION
}

\author{
DOUGLAS FRANCISCO MARCOLINO GHERARDI ${ }^{1}$ \\ CLÁUDIA ZUCCARI FERNANDES BRAGA ${ }^{1 \dagger}$ \\ VIVIAN FROES RENNÓ ${ }^{1}$
}

\author{
${ }^{1}$ INPE - Instituto Nacional de Pesquisas Espaciais \\ Caixa Postal 515 - 12201-970 - São José dos Campos - SP, Brasil \\ \{douglas, vivianfr\}eltid.inpe.br \\ $\dagger$ Deceased.
}

\begin{abstract}
It is possible to relate demographic changes resulted from our numerical experiments to environmental conditions that are likely to cause negative impacts to coral reefs. Municipalities can also be assigned with different levels of responsability in the conservation effort based on specific environmental conditions that could impact reef demographics, such as land use, and river discharge. Results of Landsat TM digital image processing, reef mapping and a metapopulation model are used to help determine the main population parameters likely to be most important for coral conservation. It is suggested here that proper conservation actions should seriously consider all environmental conditions hampering coral fecundity and larval recruitment. Results can be used to identify municipalities with potential to play a major role in improving overall conditions of the above parameters. Also, municipalities with bigger shares of available reef benthic habitat are most responsible for the maintenance of local biodiversity of organisms for which space is the main resource.
\end{abstract}

Keywords: remote sensing, image processing, metapopulation model, coral reef, conservation.

\section{Introduction}

In 1997, scientists from the Department of Oceanography at the Universidade Federal de Pernambuco (UFPE) and the Brazilian Environment Agency (IBAMA - Instituto Brasileiro do Meio Ambiente e dos Recursos Naturais Renováveis) established a protected area called 'APA Costa dos Corais', between the states of Alagoas and Pernambuco. This conservation initiative has the objective of protecting the most diverse coral community in the Southern Atlantic, its marine fauna and flora, from impacts like pollution, overfishing, sedimentation, and tourism.

A series of meetings in 1997 and 1999 culminated in a document stating the priorities for short and long term conservation of reef ecosystems. Recommendations included extensive mapping of reef buildups, and the adjacent continental shelf; organism inventory; conservation assessment; population biology of reef-building organisms (corals, coralline algae); and ecological restoration.

A cooperative scientific effort between the Brazilian National Institute for Space Research (INPE - Instituto Nacional de Pesquisas Espaciais) and UFPE initiated the mapping of the intertidal reefs within the APA Costa dos Corais using LANDSAT TM5, HRV SPOT satellite images and in situ investigation (Gherardi et al., 1999; Braga and Gherardi, 2001).

A step forward towards the use of the scientific results from the digital processing of remote sensing data and reef mapping is presented here with the identification of sensitive ecological processes acting on reef-building populations within the study area. A spatially implicit metapopulation model has been used to point out the magnitude of impacts on the production of organisms in a population considering space availability, fecundity, mortality, and recruitment conditions. In particular, the analysis of the ecological production function (sensu Roughgarden, 1997) has a special relevance in an economic context, helping to reduce 
the gap between ecological knowledge and policy mechanisms that influence environmental use.

The folowing sections will present the study area, the digital image processing techniques used for reef mapping, mapping results, model output, and the identification of specific conservation issues that should be tackled in future research.

\section{Study area}

The study area streches along $100 \mathrm{~km}$ of the Northeast Brazil coast located within the protected area called 'APA Costa dos Corais', between the states of Alagoas and Pernambuco $\left(08^{\circ} 45^{\prime} \mathrm{S}, 034^{\circ} 30^{\prime} \mathrm{W}\right.$; and $\left.09^{\circ} 25^{\prime} \mathrm{S}, 035^{\circ} 30^{\prime} \mathrm{W}\right)$ (Figure 1). The surveyed coastline includes ten municipalities between Tamandaré (PE) and Paripueira (AL). According to Maida and Ferreira (1997) the studied reef complex is characterised by three lines resembling a fringing-reef system running roughly parallel to the coast along a relatively narrow shelf 30 to $40 \mathrm{~km}$ wide. Field observation showed that the second line reefs and some of the reefs found in the first line are actually coralline-algal reefs exposed during low tide. Most of the investigated reef surfaces show extensive bioerosion produced by the echinoid Echinometra sp. and are also covered by fleshy macroalgae and articulate calcareous green algae such as Halimeda sp. A mixture of siliciclastic beach sediments and reef-derived particles are found partially covering reef tops located close to the shore.

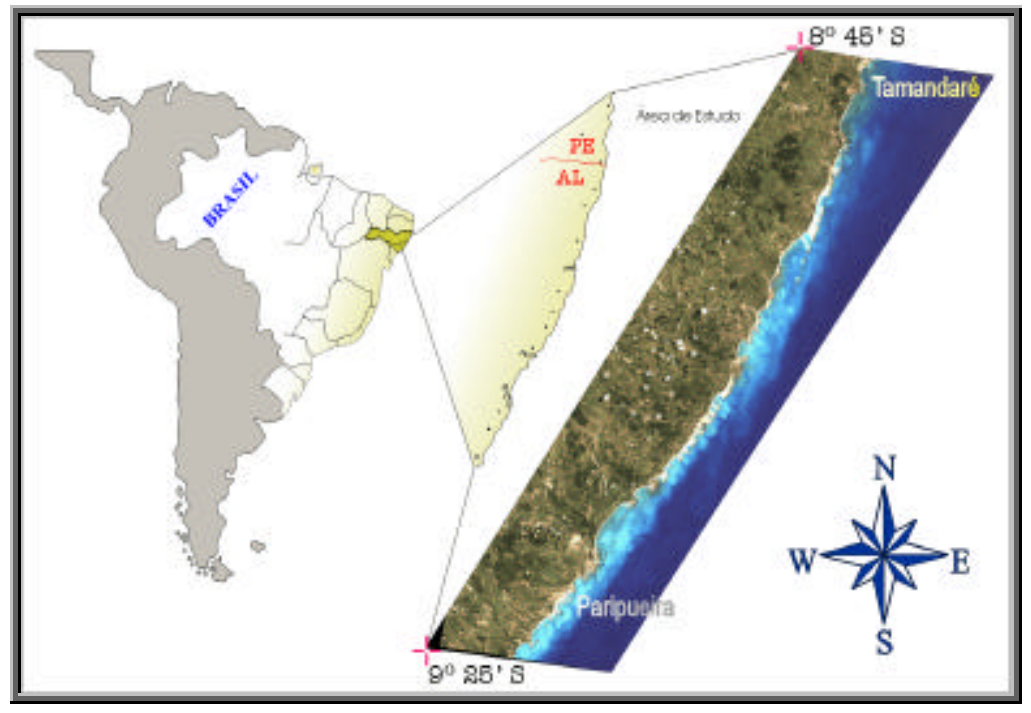

Figure 1 - Study area between the cities of Tamandaré and Paripueira.

\section{Materials and methods}

Recent Landsat TM5 (WRS 214-66, 21/09/1998) images with acceptable cloud cover were obtained during the low tide cycle from the image archives at INPE/Cachoeira Paulista (Brazil). Georeferencing and digital image processing were carried out using the image processing and geographic information system SPRING (Câmara et al., 1996). Ground control points were collected during a 6 day fieldwork in July, 1999, and additional control points were collected from topographic charts issued by IBGE (Instituto Brasileiro de Geografia e Estatística) at the scale of 1:50 000.

Images were submitted to a restoration filter and pixel size was reduced from $30 \mathrm{~m}$ to $15 \mathrm{~m}$. A low-medium pass filter was also used to remove some high frequency noise introduced by the resampling procedure. An RMS error of 0,72 pixel was achieved using a 
first order polynomial, which indicates that average positioning displacement along the images relative to the real position is $10,8 \mathrm{~m}$ with reference to the $15 \mathrm{~m}$ resolution image.

Extensive field survey included in situ inspection of almost all reef buildups found within the marine protected area. Visited reefs were described according to their surface appearance, composition and cover. A few outermost reefs (third line reefs) could not be visited because wave energy precluded their close inspection.

Digitally processed images were then visually interpreted, and vector polygons were digitized around reef buildups generating maps where surface area and perimeter of reefs could be obtained. True color composites gave the best results for the identification of reefs, and eventually bands TM1, 4, and 5 were used individually to help the identification of submerged features or reef pools. A basic legend was determined, including the following themes: 1) intertidal reef; 2) submerged reef; 3) sediment covered reef; and 4) reef pool.

\subsection{The model}

We used a single-species metapopulation model developed as a metapopulation formulation for space-limited benthic invertebrates with individuals diplaying a typical life cycle consisting of egg, pelagic larva, and benthic adult (Roughgarden, 1997). Therefore, it can be applied to model natural production of reef corals, and the influence of different parameters on the performance of the population. This formulation assumes that larvae are contained in an unstructured larval pool and adults reside on a benthic substrate, larvae are expected to recruit onto unoccupied substrate. This formulation also implies that the larval pool quickly mixes across the benthic habitat. Free space in the metapopulation formulation is defined as the area not occupied by organisms,

$$
F \equiv A-a B
$$

where A is the area of benthic habitat, a is the basal area of a single individual, and B is the number of adult organisms. The settlement (recruitment) onto empty space is given by the term cLF included in the dynamics of benthic site,

$$
\frac{d B}{d t}=c L F-\mu B
$$

where $\mathrm{c}$ is the settlement coefficient, $\mathrm{L}$ is the number of larvae in the larval pool, and $\mu$ is the benthic mortality rate. The recruitment is assumed to be proportional to both the amount of empty space and the number of larvae. The larval pool dynamics respond to the reproduction of adults, loss from larval mortality and settlement. To obtain the production function for the adults it has to be assumed that the larval population achieve equilibrium relative to the number of adults (the stock). This leads to the adult dynamics expressed as,

$$
\frac{d B}{d t}=\left[\frac{m}{1+v / c(A-a B)}-\mu\right] B
$$

where $\mathrm{m}$ is the fecundity rate of adults, and $\mathrm{v}$ is the mortality rate in the larval pool. Equations for the carrying capacity $\mathrm{K}$, and the slopes of the production function at $\mathrm{N}=0\left(\mathrm{r}_{0}\right.$, intrinsic rate of increase; $\mathrm{N}$ is the number of organisms in the population), and $\mathrm{K}=\mathrm{N}(\mathrm{r})$ are,

$$
K=\frac{c A(m-\mu)-\mu v}{c a(m-\mu)}
$$




$$
\begin{aligned}
& r_{0}=\frac{c A(m-\mu)-\mu v}{c A+v}, \text { and } \\
& r=\frac{(m-\mu)[c A(m-\mu)-\mu v]}{m v}
\end{aligned}
$$

Special care was taken to apply comparable units to model parameters in order to get meaningful results. Let a characteristic area be $1 \mathrm{~m}^{2}$, and a charcteristic time be 1 day (when necessary, data have been averaged for one year). Baseline parameters in the model are multiplied and divided by suitable combinations of these characteristic values to obtain nondimensional parameters. Baseline parameters were chosen using data from the study area whenever available, however, reef research in Brazil suffers from chronic lack of data. In order to run the model complementary data was gathered from the international literature, namely data on coral fecundity (m), and mortality rate in the larval pool (v) (see below).

\section{Results}

Improved spatial resolution of TM images obtained from digital image restoration and filtering allowed a better definition of reef boundaries as shown in Figure 2. Observations made during fieldwork highlighted the importance of spectral resolution of the blue and green TM bands as sources of information on submerged features. This was evident in our visits to the reefs during low tide to measure reef perimeter and to gauge georeferencing.
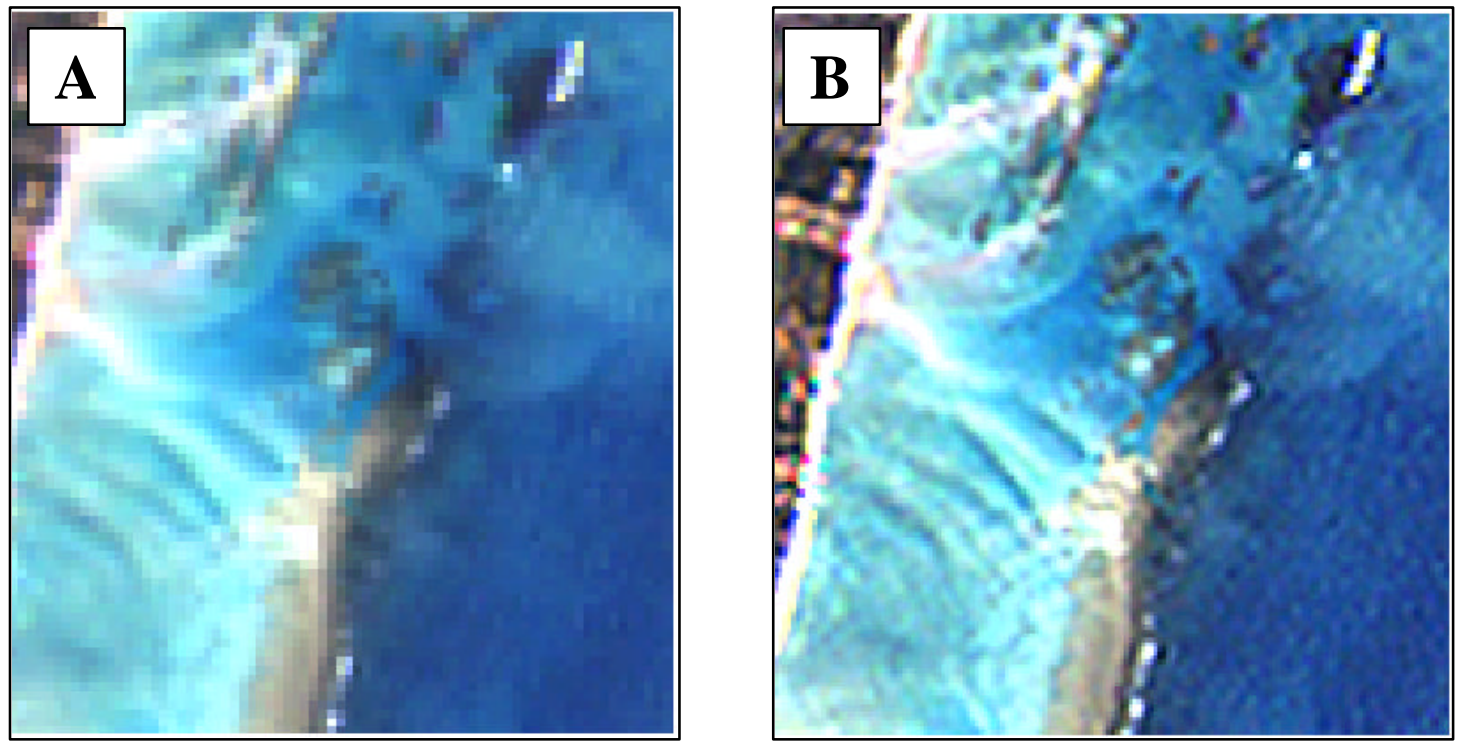

Figure 2 - Improved target definition achieved after image restoration and filtering. A) before, and B) after image processing.

Mapping could be extended horizontally with the aid of band TM1 to include shallow submerged surfaces, and improved our ability to determine the actual reef perimeter despite accessibility restrains. The visual interpretation of reef structures from color composites of TM images, suported by extensive fieldwork, can be regarded as an acceptable aproximation to ground truth (Figure 3), though not always applicable ( $c f$. Green et al., 2000). 

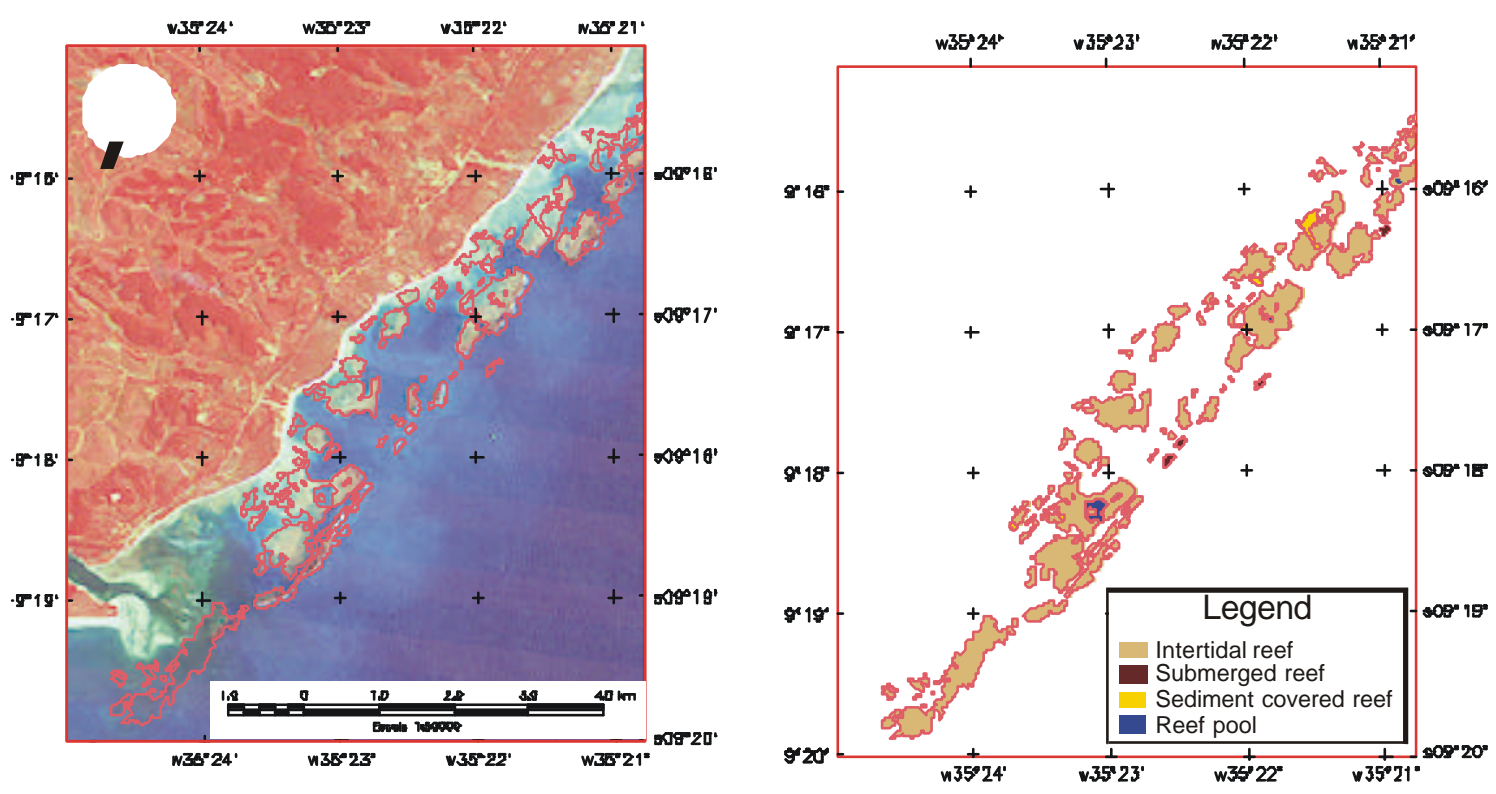

Figure 3 - Example of image interpretation and reef mapping result.

A total of ten municipalities are included in the potected area, and for each one a number of vector polygons are assigned. It is possible therefore to calculate the reef area and reef perimeter corresponding to the projected coastline of the concerned municipality. Assuming an average reef height of $2 \mathrm{~m}$ it is then possible to calculate the total area of benthic habitat (A), necessary to run the metapopulation model (Table 1).

Table 1 - Spatial data generated from reef mapping and GIS metric operations.

\begin{tabular}{|l|c|c|c|c|}
\hline Municipality & Reef area $\left(\mathrm{m}^{2}\right)$ & Reef perimeter $(\mathrm{m})$ & $\begin{array}{l}\text { Area of benthic } \\
\text { habitat }\left(\mathrm{A}, \mathrm{m}^{2}\right)\end{array}$ & $\begin{array}{l}\text { Number of } \\
\text { polygons }\end{array}$ \\
\hline Tamandaré & 2961379,48 & 63473,88 & 126947,75 & 52 \\
\hline Barreiros & 1519647,80 & 28040,16 & 56080,33 & 26 \\
\hline São José da Coroa Grande & 2244935,14 & 41768,73 & 83437,46 & 16 \\
\hline Maragogi & 6142910,24 & 111777,27 & 223554,54 & 122 \\
\hline Japaratinga & 6131952,84 & 89874,46 & 179748,92 & 56 \\
\hline Porto de Pedras & 4720827,61 & 64798,11 & 129596,23 & 33 \\
\hline São Miguel dos Milagres & 2710420,63 & 49477,94 & 98955,87 & 43 \\
\hline Passo de Camaragibe & 4271946,01 & 63321,25 & 126642,51 & 37 \\
\hline Barra de Santo Antônio & 3125449,20 & 57304,15 & 114608,29 & 38 \\
\hline Paripueira & 2268260,87 & 46620,06 & 93240,13 & 33 \\
\hline
\end{tabular}

Numerical experiments (Figure 4, 5, and 6) were carried out simultaneously for all 10 municipalities and no attempt has been made to normalize reef area or reef perimeter because the model has a spatially implicit formulation. Therefore, it is important, as far as the production function is concerned, that results should bear a strict relation with the actual area of benthic habitat. We have chosen the baseline nondimensional parameters to run the model which are relevant to corals. These are:

A: area of substrate available for adults per municipality obtained from the reef mapping as shown in Table 1.

a: area occupied by a single coral adult. Let $\mathrm{a}=0.03 \mathrm{~m}^{2}$, for an individual with $0.2 \mathrm{~m}$ diameter.

B: number of coral colonies within the study area. 
m: the rate of larval production by an adult. According to Harrison et al. (1984), a plausible number of larva production per year is 60000 larvae, considering reproduction takes place in periods of four days along four months (2000 larvae per period), averaged for 360 days, gives 166,7 larva day ${ }^{-1}$ ind. $^{-1}$.

c: the larval settlement coefficient. In the model, cFL equals the settling rate, which for Tamandaré is 0,156 recruits $\mathrm{m}^{-2} \mathrm{~d}^{-1}$ (calculated from Maida and Ferreira, 1995). Let $\mathrm{F}$ equal $1 \mathrm{~m}^{2}$, and $\mathrm{L}$ equal $1 \%$ of $\mathrm{m}$ (i.e., $1 \%$ of the larvae is competent), therefore, c equals 0,094 .

$\boldsymbol{\mu}$ : the death rate of adults, estimated from the rate of death of recruits reported by Maida and Ferreira (1995). The actual death rate is likely to be lower, but an estimate of 0,1 individual $\mathrm{d}^{-1} \mathrm{~m}^{-2}$ was chosen.

$\mathbf{v}$ : the death rate of the larvae. A value of 8,3 was chosen assuming that $5 \%$ of the larva produced per individual, estimated from $\mathrm{m}$, dies every day.
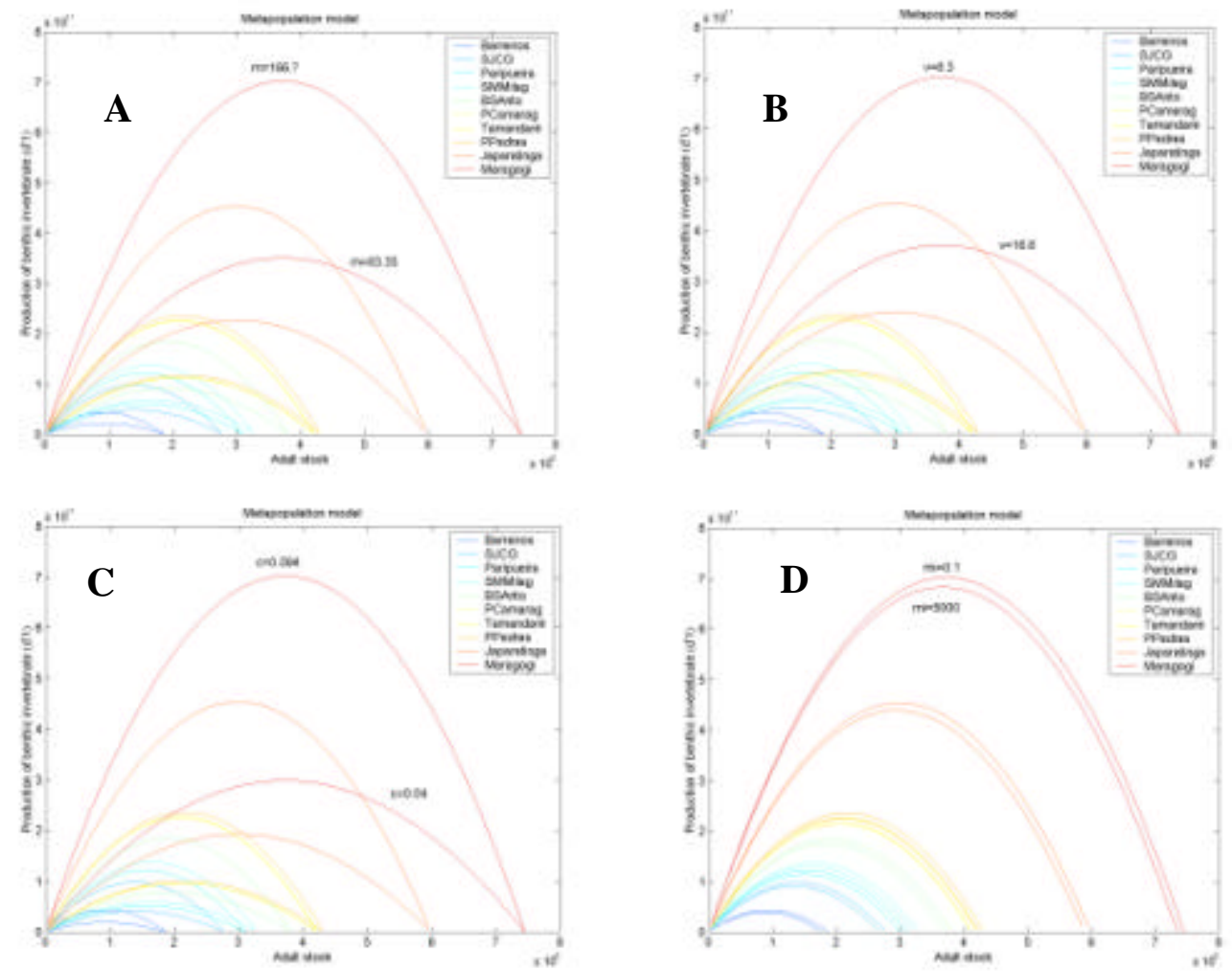

Figure 4 - Results of the numerical experiments using the production function. Baseline model yields are plotted together with changes in one of the nondimensional parameters.

Numerical experiments of the production function have been carried out and results of baseline yields compared separately with $50 \%$ decrease in $\mathrm{c}, \mathrm{m}$, and $50 \%$ increase in $\mathrm{v}$, and $\mu$. In all cases an unfavourable environmental scenario was sought (see Figure 4). The production function seems to be more sensitive to changes in the settlement coefficient, closely followed by the mortality rate in the larval pool and the fecundity rate. In contrast, the death rate of adults showed only a slight reduction in the production function despite a five orders of magnitude increase.

Experiments have also been carried out for $\mathrm{r}_{0}$ (Figure 5), and $\mathrm{r}$ (Figure 6). The intrinsic rate of increase responds proportionally to changes in fecundity (shown only in the left graph) but it is non linear for $\mathrm{c}$ and linear for $\mathrm{v}$. Results for $\mathrm{r}$ show a positive linear trend with varying c, and a hyperbolic shape when plotted against $\mathrm{v}$. 

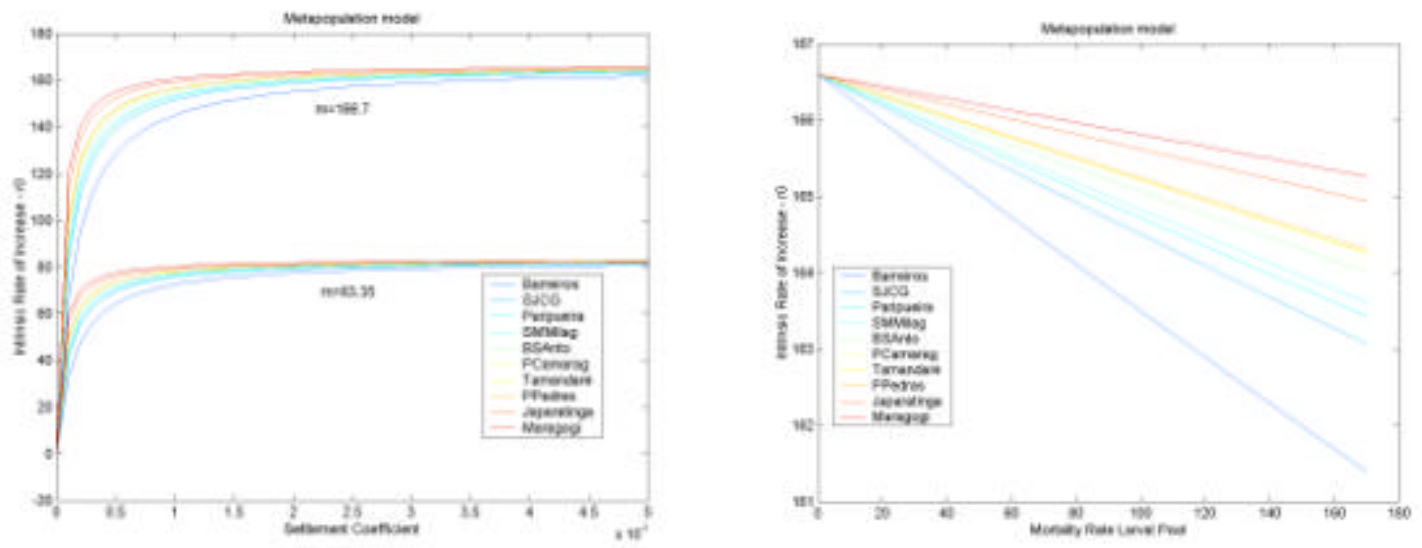

Figure 5 - Results of numerical experiments using the intrinsic rate of increase. Note the difference in the stabilizing thresholds for $r_{0}$ when fecundity is reduced (left graph); $r_{0}$ displays a negative linear trend under increased mortality rate of larvae (right graph).
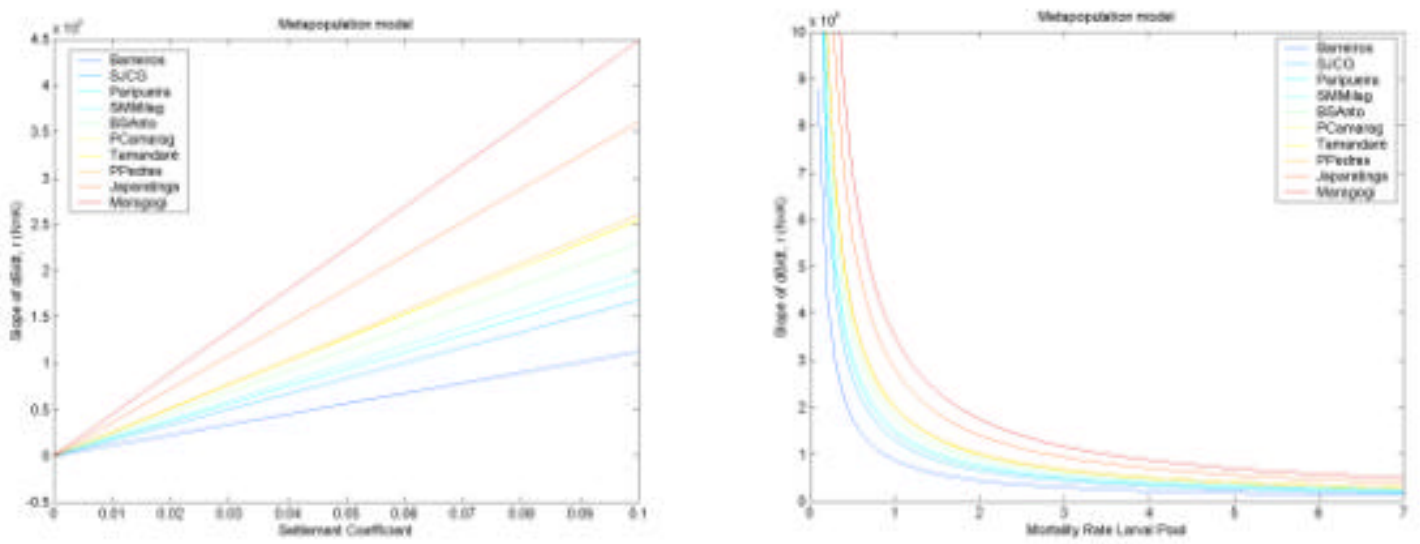

Figure 6 - Contrasting with Fig. 5, r linearly increases with increasing recruitment, and rapidly decreases with only a slight drop in larval mortality.

\section{Discussion}

The production of coral individuals is most severely depressed by the reduction of larval settlement (Fig. 4A), but production is also negatively impacted by the reduction in fecundity, and increase in larval mortality (Fig. 4B, C). Surprisingly, the production function was insensitive to benthic mortality rate (Fig. 4D), suggesting that production may be chiefly governed by free space and recruitment. Coral production tend to follow the overall rate of decrease $(50 \%$ in this experiment) in nondimensional parameters. More precisely, the reduction in $\mathrm{c}$ shifted the production peak below the $50 \%$ line, whereas parameters such as $\mathrm{v}$ and $\mathrm{m}$ shifted the production peak close to or slightly above that line. Another important feature identified in our results indicates that the larger the available benthic habitat (computed per municipality), the larger the loss in natural production. These results suggest that factors that impede coral larvae settlement or reduce the accessibility to substrate may cause severe impacts on the ability of a population to achieve its highest possible yields jeopardizing the resilience of threatened coral populations.

The intrinsic rate of increase, $\mathbf{b}$, of a coral population is strongly influenced by the rate of larval production, and tends to rapidly stabilize at a relative low settlement coefficient. But in small reef areas settlement must be much higher than in large areas to achieve maximum $\mathrm{r}_{0}$. Larval and adult mortality have not as much influence on $r_{0}$ as fecundity and recruitment, so much so that if fecundity is halved the 10 intercept also experience a $50 \%$ decrease (not shown 
in Fig. 5). Although fecundity appears to be an important factor in the establishment of a new population, or for the recovery of heavily impacted one, experiments with the production function clearly shows that proper recruitment conditions should prevail in order to allow the generation of an stable adult stock.

Population growth at the carrying capacity $(\mathrm{K}=\mathrm{N})$ of the environment can, in contrast with the scenario where $\mathrm{N}=0$, be severely depressed with minor increases in the mortality rate of the larval pool. Production of individuals in a stable population can also be gradually brought down to zero with decreasing recruitment (Fig. 6).

It seems that proper conservation actions should seriously consider all environmental conditions hampering coral fecundity and larval recruitment, and identify municipalities that could play a major role in improving overall conditions of the above parameters. Also, municipalities with bigger shares of available reef benthic habitat are most responsible for the maintenance of local biodiversity of organisms for which space is the main resource.

We believe that our results could be used to help direct research efforts into key aspects of population ecology relevant to reef conservation in Brazil. Validation of these results through ecological experiments in the field is of paramount importance for future development of metapopulation models.

\section{Conclusions}

1) Reef mapping using remote sensing data can play a fundamental role in generating spatial information for metapopulation modeling.

2) Factors that impede coral larvae settlement or reduce its accessibility to substrate may cause severe impacts to coral population.

3) The intrinsic rate of increase of a coral population, 10 , is strongly influenced by the rate of larval production.

4) Population growth at the carrying capacity is sensitive to the mortality rate of the larval pool.

\section{References}

Camara G., Souza R.C.M., Freitas U.M., Garrido J. SPRING: Integrating remote sensing and GIS by objectoriented data modelling. Computers \& Graphics, v. 20; p. 395-403; 1996.

Braga C.Z.F., Gherardi D.F.M. (2001). Mapeamento de recifes costeiros utilizando imagens orbitais. In: Simpósio Brasileiro de Sensoriamento Remoto, 10., Foz do Iguaçu, abr. 2001. Anais. São José dos Campos: INPE, 2001. Sessão Oral. p. 759-767; URLib Repository: <dpi.inpe.br/lise/2001/09.19.12.05>.

Gherardi D.F.M., Braga C.Z.F., Morelli F. Reef conservation in Brazil: remote sensing and ground truthing. Reef Encounter, v. 26; p. 32-33; 1999.

Harrison P.L., Babcock R.C., Bull G.D., Oliver J.K., Wallace C.C., Willis B.L. Mass spawning in tropical reef corals. Science; v. 223:1186-1189; 1984.

Maida M., Ferreira B.P. Estudo preliminar sobre o assentamento de corais em um recife na Baía de TamandaréPE. Boletim Técnico-Científico do CEPENE; v. 3; p. 23-36; 1995.

Maida M., Ferreira B.P. Coral Reefs of Brazil: an overview. In: $8^{\text {th }}$ International Coral Reef Symposium, Panama, June 1997. Proceedings; v. 1; p. 263-274.

Green E.P., Clark C.D., Edwards A.J. Image classification and habitat mapping. In: Edwards A.J. (ed.) Remote Sensing Handbook for Tropical Coastal Management, Costal Management Sourcebooks 3, UNESCO Publishing, France. p141-154, 2000.

Roughgarden J. Production function from ecological populations: a survey with emphasis on spatially implicit models. In: Tilman D. and Kareiva P. (eds.) Spatial Ecology, Monographs in Population Biology 30, Princeton University Press, Princeton, pp. 204-232, 1997. 